\title{
Single vs. multi-cone synchronizers with carbon friction lining - a comparison of load limits and deterioration behavior
}

\author{
U. Stockinger ${ }^{1}(\mathbb{D}) \cdot$ T. Schneider $^{1}(\mathbb{D}) \cdot$ H. Pflaum ${ }^{1}$ (D) $\cdot$ K. Stahl $^{1}$ (D)
}

Received: 10 April 2019 / Published online: 30 June 2020

(c) The Author(s) 2020

\begin{abstract}
Synchronizers are widely used in gear boxes of car and truck transmissions. Optimizing costs and improving the efficiency of gear boxes require knowledge about the relative load limits of single and multi-cone synchronizers with carbon friction linings and their corresponding deterioration mechanisms. Load limits for single and multi-cone synchronizers with carbon friction lining used in cars were determined experimentally using the component test rig SSP-180 and compared against each other. Different load stages were run in life cycle tests and the influences of pressure, sliding velocity, friction work, frictional power and oil temperature were investigated. The synchronizers' failure mode is described and the novel specific value $\mu_{\text {min,grad }}$ is introduced that is able to quantify the deterioration of different synchronizer systems. During life cycle tests at the same specific load level, the single cone synchronizers, contrary to expectations, displayed greater damage compared to the multi-cone synchronizers. Calculations of the friction surface temperature in thermo-mechanical simulations, in combination with experiments on the test rig, show that the maximum temperature during the engagement has a significant influence on deterioration and endurance life of synchronizers with carbon friction lining.
\end{abstract}

\section{Einfach- vs. Mehrfachkonus-Synchronisierungen mit Carbon-Reibbelag - Ein Vergleich von Belastungsgrenzen und Schädigungsverhalten}

\section{Zusammenfassung}

Synchronisierungen werden in sehr großen Stückzahlen in PKW- und NKW-Getrieben eingesetzt. Um Kosten zu optimieren und die Effizienz von Getrieben zu steigern, ist es entscheidend die relativen Belastungsgrenzen von Einfachim Vergleich zu Mehrfachkonus-Synchronisierungen mit Carbon-Reibbelag sowie die zugeordneten Schädigungsmechanismen zu kennen. Belastungsgrenzen von Einfach- und Mehrfachkonus-Synchronisierungen wurden experimentell auf dem Prüfstand SSP-180 ermittelt und vergleichend bewertet. In Einstufen-Dauerschaltversuchen wurden unterschiedliche Lastniveaus betrachtet und die Einflüsse von Pressung, Gleitgeschwindigkeit, Reibarbeit, Reibleistung und Öleinspritztemperatur auf die Schädigung bestimmt. Die Ausfallursachen der verschiedenen Synchronisierungen werden beschrieben und der neue Kennwert $\mu_{\text {min,grad }}$ eingeführt, um das Schädigungsverhalten von Einfach- und Mehrfachkonus-Synchronisierungen quantitativ zu vergleichen. Entgegen den Erwartungen zeigt die untersuchte PKW-Einfachkonus-Synchronisierung bei gleichen spezifischen Beanspruchungen eine stärkere Schädigung des Reibsystems in den Dauerschaltversuchen als die Mehrfachkonus-Synchronisierungen. Thermo-mechanische Simulationen in Kombination mit Prüfstandversuchen zeigen, dass die Maximaltemperatur während einer Schaltung einen signifikanten Einfluss auf das Schädigungsverhalten und damit auf die Lebensdauer von Synchronisierungen mit Carbon-Reibbelag hat.

U. Stockinger

Stockinger@fzg.mw.tum.de

T. Schneider

Schneider@fzg.mw.tum.de

H. Pflaum

Pflaum@fzg.mw.tum.de
K. Stahl

Stahl@fzg.mw.tum.de

1 Forschungsstelle für Zahnräder und Getriebebau-FZG, TU München, Boltzmannstraße 15, 85748 Garching bei München, Germany 


\section{Introduction}

Synchronizers are widely used in gear boxes of car and truck transmissions. These machine elements synchronize the rotational speed of the output shaft and the gear wheel to be engaged to ensure smooth gear changing. For the synchronization process, a cone clutch with up to three friction surfaces is used to accelerate or decelerate input shaft and gear wheel, which have different rotational speeds. After synchronization, torque is transferred by a positive dog clutch. The synchronization process is described in detail by $[1,2]$. Multi-cone synchronizers are especially used in lower gears as their torque capacity is significantly higher than that of single cone synchronizers. Higher friction torque results in faster shifting times, but the greater complexity of multi-cone synchronizers makes them more expensive and can raise the drag torque [3]. Fig. 1 shows a typical double cone synchronizer and its components. The blocker and the inner ring are coupled together by lugs on the inner ring and pockets on the blocker ring. Additionally the intermediate ring is coupled with the gear wheel by lugs and the corresponding pockets on the gear wheel. Torque generated between the axial plane surfaces of the inner ring and the gear wheel is much smaller than that between the friction surfaces. It contributes approximately 5\% to the overall torque of the whole synchronizer [4]. A triple cone synchronizer has an additional conical friction surface on the inner ring which is in contact with a cone on the gear wheel. Research on multi-cone synchronizers is reported by [4-9]. Erdmann [4] investigates the efficiency of a synchronizer, defined as the quotient of measured to calculated friction torque. Experiments in [4] measure the lowest efficiency for an increasing shifting force and the highest efficiency for a decreasing shifting force during the engagement. Other parameters, like surface pressure, sliding velocity, and temperature influence the efficiency to

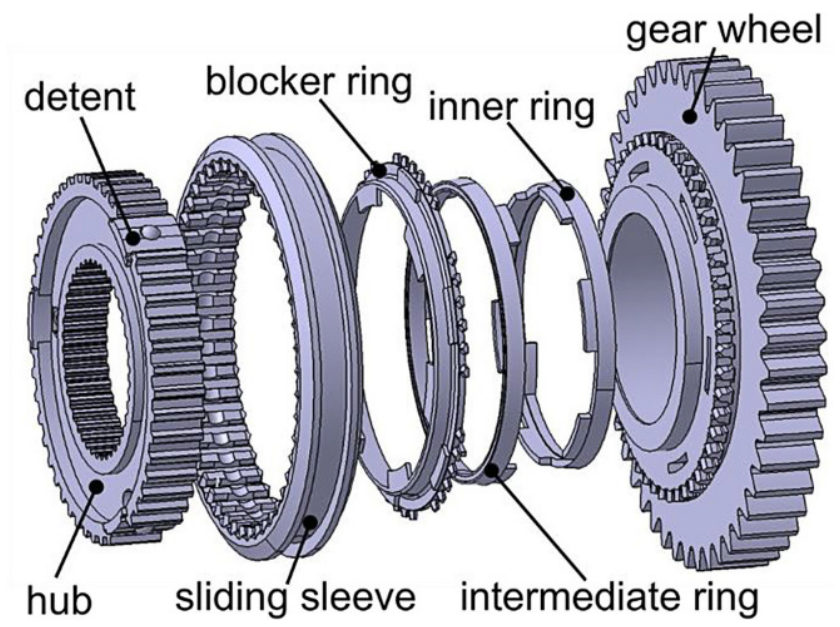

a lesser degree. Sykes [5] describes the development process of new brass triple cone synchronizers and associated problems during testing and their respective solutions. Abdel Halim et al. [6] demonstrates the advantages of multicone synchronizers compared to single cone synchronizers, like greater torque capacity theoretically, and on the test rig.

For a safe synchronization process, the friction torque has to exceed the blocking release torque (index torque) when the rotational speeds are different [1]. The friction torque $T_{F}$, the torque that acts on the friction surfaces and synchronizes the rotational speed, is calculated by [2]:

$T_{F}=n \cdot F_{a x} \cdot \frac{d_{m} \cdot \mu}{2 \cdot \sin \alpha}$

$F_{a x}$ is the axial force on the blocker ring, $\mu$ the coefficient of friction $(\mathrm{CoF})$ between the cones, $\mathrm{d}_{\mathrm{m}}$ is the mean cone diameter, $n$ the amount of friction surfaces, and $\alpha$ is the cone angle (angle between cone and cone axis). The equation assumes that for multi-cone synchronizers, $\mu$ is the same on each friction surface and $\mathrm{d}_{\mathrm{m}}$ is the mean value of each friction surface's mean cone diameter. The blocking release torque $\mathrm{T}_{\mathrm{Z}}$ is [2]:

$T_{Z}=F_{a x} \cdot \frac{d_{D}}{2} \cdot \frac{1-\mu_{D} \cdot \tan \frac{\beta}{2}}{\mu_{D}+\tan \frac{\beta}{2}}$

$d_{D}$ is the pitch diameter (interface between blocker teeth and sliding sleeve), $\mu_{\mathrm{D}}$ is the coefficient of friction of the chamfers, and $\beta$ the chamfer angle (angle between both tooth flanks). To block the gear engagement during synchronization successfully, $T_{F}>T_{Z}$, and relation (3) has to be satisfied. If the static $\mathrm{CoF}$ between the cones exceeds $\tan \alpha$, self-locking can occur [2].

$\mu>\frac{d_{D}}{n \cdot d_{m}} \cdot \sin \alpha \cdot \frac{1-\mu_{D} \cdot \tan \frac{\beta}{2}}{\mu_{D}+\tan \frac{\beta}{2}}$

Different failure modes of synchronizers cause clashing. A clash happens when the sliding sleeve tries to mesh with the clutch teeth of the gear wheel, while there is still a significant rotational speed difference between these parts. Typical failure modes are described by [1, 2, 10-14] and are summarized as follows:

- The coefficient of friction on the friction surfaces is too low during synchronization.

- Wear on the friction surfaces reduces the axial gap between blocker ring and gear wheel to zero. Torque is not transferred through cones but the plane face.

- Components of synchro unit break (e.g. blocker ring).

- Chamfer angle of blocking ring changes due to wear.

Fig. 1 Double Cone Synchronizer 
- Desynchronization after free flight phase because of high drag losses.

- Inadequate pre-synchronization.

In applications with high loads, Carbon is used as friction lining because it can stand higher surface pressure, friction work and power compared to other friction linings. Due to the low thermal conductivity of carbon friction linings, multi-cone synchronizers, which have small thermal mass and worse cooling compared to single cone systems, exhibit high surface temperatures during the engagement which damage both friction lining and lubricant.

Acuner et al. [11] investigate failure modes of single cone synchronizers with carbon friction linings and define a lubricant related and a friction lining related failure mode. Due to high surface temperatures, crack products from the lubricant block the friction lining's pores and significantly reduce the core roughness depth sRk. The reduction of sRk correlates well with the reduction of $\mu_{\min }$ (minimum CoF in the range of $5 \ldots 90 \% \mathrm{~V}_{\text {gmax }}$ during an engagement). This reduces the $\mathrm{CoF}$ at the beginning of the synchronization process. Relation (3) is not satisfied, which results in early clash of the synchronizer. Osanai et al. [15] and Maeda et al. [16] describe the same effect for paper friction linings. A second failure mode is the deterioration of friction linings' matrix. Exceeding a specific temperature level causes this type of deterioration. It results both in lower mechanical strength and reduced adhesion of the carbon particles for particle based friction linings. Acuner et al. [11] observe breaking fibers for woven friction linings in SEM investigations.

Häggström [17] describes that over $200^{\circ} \mathrm{C}$ focal temperature, hot spots occur for the CFRP carbon friction lining. Degradation of performance and significant wear start around $230 \ldots 250^{\circ} \mathrm{C}$. The tests were stopped after 10,000 cycles and did not lead to failure of the synchronizers.

Several publications describe thermo-mechanical simulations of synchronizers [4, 12, 14, 18-24]. Erdmann [4], based on preliminary work from Spreckels [20] and Neudörfer [19], who set up the model and determined material parameters for different friction linings, conducts 2D and 3D thermo-mechanical simulations on multi-cone synchronizers. The pressure distribution on the friction surface was inhomogeneous both in axial and circumferential direction due to the inhomogeneous cross section of the blocker ring. Häggström et al. [24] describes his approach to simulate the thermal behavior of a single cone synchronizer and studies influencing parameters on the maximum surface temperature. Straightness and initial angle difference influence the maximum friction surface temperature more than the bulk design of the synchronizer. Häggström et al. [23] extend their work and introduce a methodology to validate their simulations. Furthermore Häggström et al.
$[17,25]$ investigate influences of manufacturing tolerances, like relative cone angles or out-of-roundness for Carbon and Molybdenum (Mo) friction linings. An out of roundness leads to higher maximum surface temperatures. The maximum surface temperature can be optimized by a suitable cone angle. Acuner et al. [18] and Neudörfer [19] confirm this in their research.

However, a lot of research on synchronizers has been conducted, the performance of single and multi-cone synchronizers with Carbon friction lining has not been investigated in detail. This study aims to determine load limits and introduces an evaluation method to compare the performance of different synchronizer systems. An extract from these results was presented at Dritev-Getriebe in Fahrzeugen 2019 in Bonn [26].

\section{Method}

Load limits for single and multi-cone synchronizers with carbon friction lining are determined experimentally using the component test rig SSP-180. Therefore, the chosen hypothetical test conditions and loads are significantly higher than the typically specified lifetime transmission conditions in order to artificially generate overload and misuse to generate failures.

\subsection{Test rig, synchronizers and lubricant}

The endurance tests were performed on the ZF/FZG synchronizer standard test rig SSP-180. Fig. 2 shows the con-

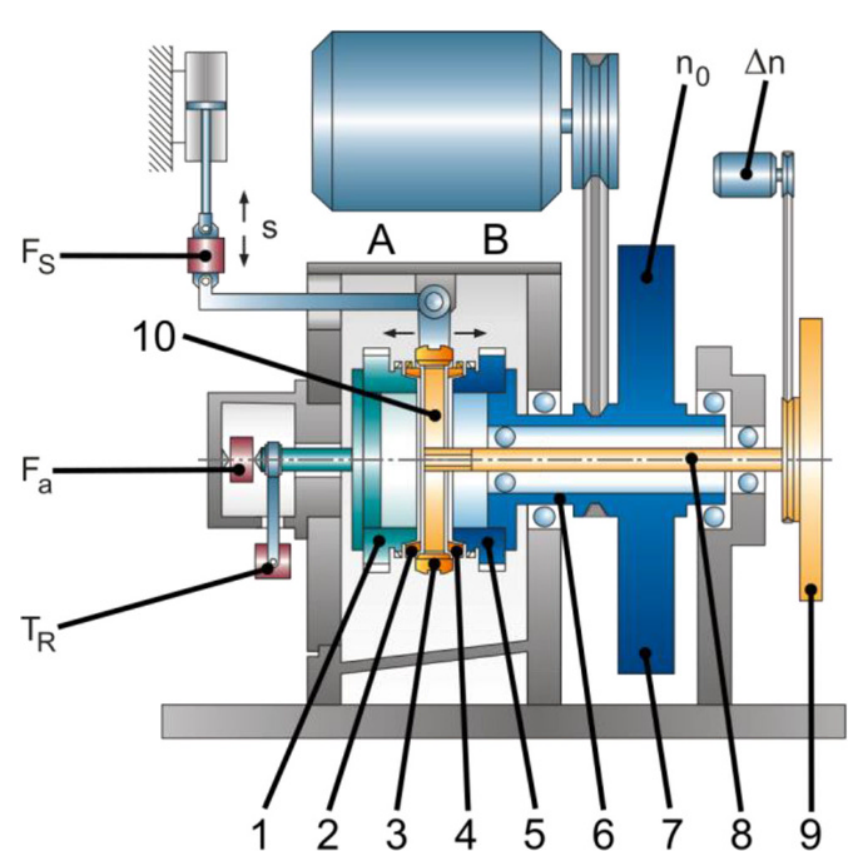

Fig. 2 Test rig SSP-180 according to [12] 
Fig. 3 Synchronizers. a EK73, b DK73, c TK73
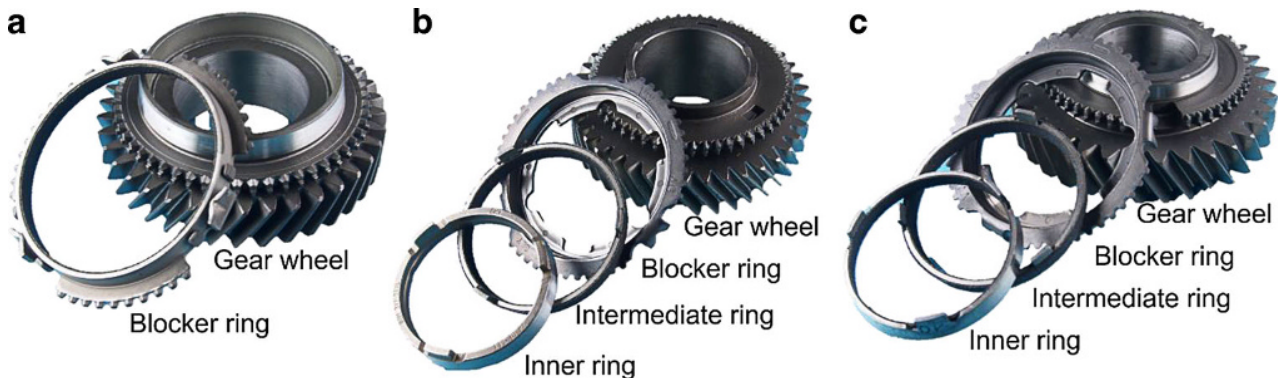

cept of the test rig. For each test, two sets of synchronizers (1-2) and (4-5) are mounted to the test rig on each side (A/B) of the sliding sleeve (3). The gear wheel (1) on the A-side (left) is stationary. Gear wheel (5) and inertia (7) are fixed to shaft (6) and rotate with constant rotational speed. Inertia (9), which is fixed to shaft (8) together with hub (10), is changed according to the required friction work of the test. The synchronizers' friction behavior is measured on the A-side of the test rig. During one cycle, the sliding sleeve moves from the A- to the B-side and back and engages the two synchronizers consecutively. Moving the sliding sleeve to the A-side breaks shaft (8) and inertia (9) down to standstill. Engaging synchronizer (4) accelerates (8-9) up to $\mathrm{n}_{0}$.

The tests were run with single (EK73), double (DK73) and triple (TK73) cone synchronizers with a dual layer carbon friction lining from the same modular system, shown in Fig. 3. Table 1 summarizes their geometrical parameters.

The performance tests were conducted with a manual transmission fluid MTF-Car from series production (kinematic viscosity $27.6 \mathrm{~mm}^{2} / \mathrm{s}$ at $40^{\circ} \mathrm{C}, 6.1 \mathrm{~mm}^{2} / \mathrm{s}$ at $100^{\circ} \mathrm{C}$ ) typically used in cars.

Each test starts with 50 running-in cycles on $50 \%$ of the load stages' axial force and rotational speed. Afterwards, a single step life cycle test is performed until the synchronizer fails because of clashing. The test rigs' vibration monitor detects clashes and ends the test. Similar specific load parameters are used, to compare the friction performance of different synchronizer systems. Table 2 summarizes the tested load stages for the three types of synchronizers. The axial force between the three different synchronizer systems varies corresponding to the different friction areas. Both

Table 1 Geometry parameters of tested synchronizers

\begin{tabular}{lllll}
\hline & Friction surface & EK73 & DK73 & TK73 \\
\hline Average & Outside & 72.3 & 73.0 & 73.0 \\
diameter/mm & Middle & - & 66.9 & 66.9 \\
& Inside & - & - & 61.7 \\
Width of & Outside & 8.0 & 6.5 & 6.5 \\
friction & Middle & - & 7.1 & 7.1 \\
surface/mm & Inside & - & - & 6.6 \\
& - & 7.5 & 7.5 & 7.5 \\
Cone angle ${ }^{\circ}$ & - & & &
\end{tabular}

Table 2 Load stages for different synchronizer systems (EK73, DK73, TK73)

\begin{tabular}{llll}
\hline $\begin{array}{l}\text { Load } \\
\text { stage }\end{array}$ & $\begin{array}{l}\text { Mean. contact } \\
\text { pressure } \\
\text { p/N/mm }\end{array}$ & $\begin{array}{l}\text { Mean. sliding } \\
\text { velocity } \\
\mathrm{v}_{\mathrm{g}, \mathrm{max}} / \mathrm{m} / \mathrm{s}\end{array}$ & $\begin{array}{l}\text { Spec. friction } \\
\text { work } \\
\mathrm{q} / \mathrm{J} / \mathrm{mm}^{2}\end{array}$ \\
\hline LS1 & 4.0 & 4.5 & 0.7 \\
LS2 & 4.0 & 6.5 & 0.7 \\
LS3 & 4.0 & 8.0 & 0.7 \\
LS4 & 4.0 & 4.5 & 0.9 \\
LS5 & 4.0 & 6.5 & 0.9 \\
LS6 & 4.0 & 8.0 & 0.9 \\
LS7 & 4.0 & 4.5 & 1.1 \\
LS8 & 4.0 & 6.5 & 1.1 \\
LS9 & 4.0 & 8.0 & 1.1 \\
\hline
\end{tabular}

contact pressure and sliding velocity give the mean values over all friction surfaces. The oil flow through a perforated plate cools the synchronizer from the top. If not mentioned differently, the oil temperature was kept at $\vartheta_{\text {oil }}=80^{\circ} \mathrm{C}$ and the oil flow at $\mathrm{V}_{\text {oil }}=5 \mathrm{l} / \mathrm{min}$. The cycle time was adapted that the specific mean power per cycle is about $60 \mathrm{~mW} / \mathrm{mm}^{2}$.

As an example, Fig. 4 shows the measured signals of V53 (cycle 120) on LS9 (EK73).

\subsection{Failure mode and evaluation of tests}

All synchronizers failed because the values of $\mathrm{CoF}$ at the beginning of the engagement were too low. As an example, Fig. 5 shows the development of the friction characteristic during one test on LS9 for the triple cone synchronizer. Over the endurance life, the CoF almost does not change at low sliding velocities, but significantly decreases at high sliding velocities. The axial wear of all synchronizers was less than $0.4 \mathrm{~mm}$ and thus not the reason for the failure of the synchronizers.

The minimum $\operatorname{CoF} \mu_{\text {lock }}$ at which $\mathrm{T}_{\mathrm{F}}$ equals $\mathrm{T}_{\mathrm{Z}}$, highly differs between single and multi-cone synchronizers (Eq. 3). Although, the blocker ring's chamfer angle $\beta$ differs between the investigated double/triple and the single cone synchronizers, $\mu$ of the two multi-cone synchronizers can decrease further until the synchronizer fails, than for the single cone synchronizer. $\mu_{\text {lock }}$ is estimated by Eq. 3 for 
Fig. 4 Measured signals cycle 120 of EK73, LS9, V53, MTF-Car

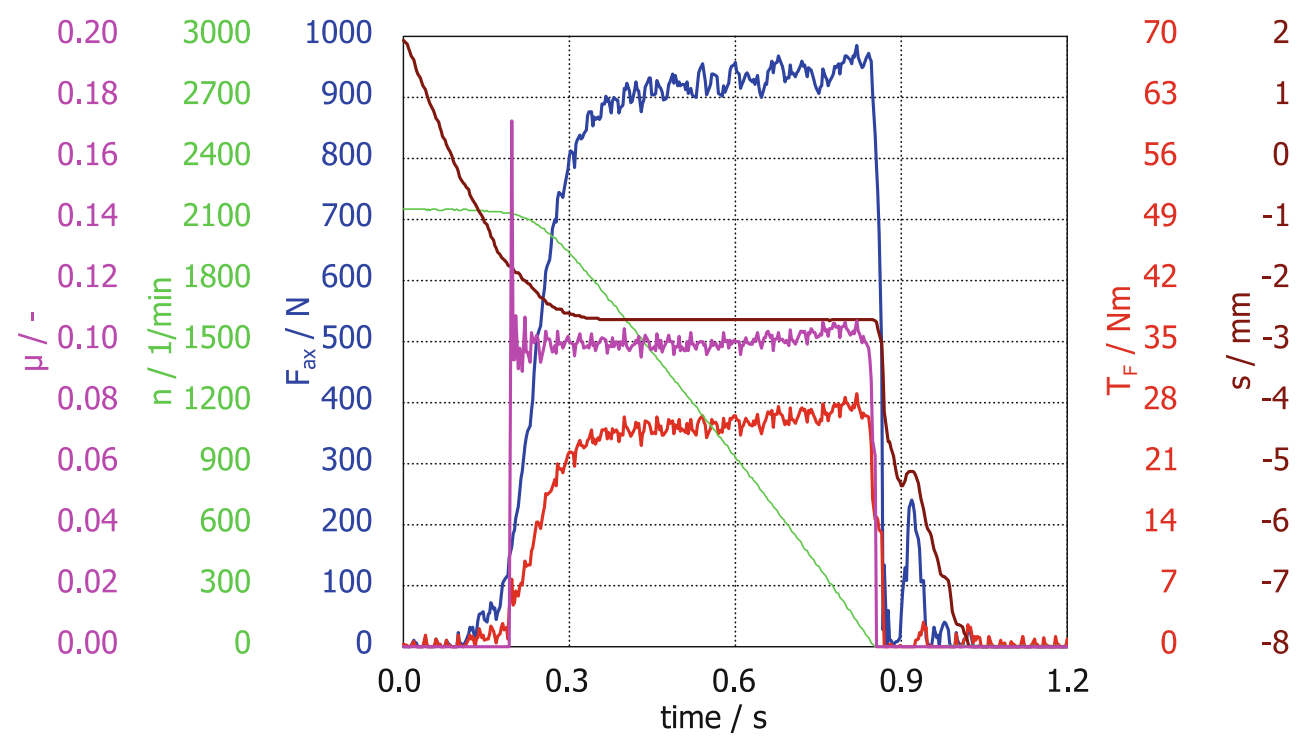

the single cone $\mu_{\text {lock }}=0.083$, the double cone $\mu_{\text {lock }}=0.069$ and the triple cone synchronizer $\mu_{\text {lock }}=0.049 . \mu_{\mathrm{D}}$ is assumed constant in this calculation.

The friction behavior is evaluated using the following specific values:

- $\mu_{\text {avg: }}$ average CoF over the interval $60-0 \% \mathrm{v}_{\mathrm{g}, \max }$

- $\mu_{\min }$ : minimum CoF in the interval 5-90\% $\mathrm{v}_{\mathrm{g}, \max }$

- $\mu_{\min , 97}$ : minimum CoF in the interval 5-97\% $\mathrm{v}_{\mathrm{g}, \max }$

- $N$ : cycles till failure of the synchronizer

Fig. 5 Change of friction char-

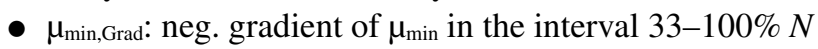

- $\mu_{\mathrm{min}, \mathrm{Grad} 97}$ neg. gradient of $\mu_{\mathrm{min}, 97}$ in the interval $33-100 \%$ $N$

As the blocking safety between single, and multi-cone synchronizers differ, the cycles $N$ until failure of different systems cannot be compared. This is why the specific value $\mu_{\mathrm{min}, \mathrm{Grad}}$, which describes the negative slope of the minimum CoF's regression line in the trend plot, was developed to acteristic during endurance life of TK73, LS9, V150, MTF-Car

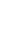

$-2$

$$
-3
$$

Fig. 6 Trend plot of $\mu_{\text {avg, }} \mu_{\mathrm{min}}$, $\mu_{\min , 97}$ for DK73, LS9, V17, MTF-Car

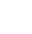

(1) 
describe and compare the deterioration behavior of different synchronizer systems. This specific value describes the change of $\mu_{\min }$ during the endurance life and is similar to the specific values suggested by [12]. As $\mu_{\text {min,grad }}$ just covers the minimum CoF in a range of 5-90\% $\mathrm{v}_{\mathrm{g}, \max }$ and the minimum CoF occurs at higher sliding speeds than $90 \% \mathrm{v}_{\mathrm{g}, \max }$, the range of $\mu_{\text {min,97 }}$ was extended to $5-97 \% v_{g}$,max. As an example, Fig. 6 shows the trend plot of $\mu_{\text {avg }}, \mu_{\min }, \mu_{\min , 97}$ and

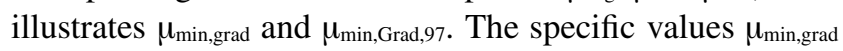
and $\mu_{\min , \text { Grad,97 }}$ are small, as they describe the hypothetical decrease of $\mu_{\min } / \mu_{\min , 97}$, if the test would run up to 100,000 cycles. For all diagrams, $\mu_{\text {min,grad }}$ and $\mu_{\text {min,Grad,97 }}$ are multiplied by 100,000 .

\subsection{Thermo-mechanical simulation}

The maximum surface temperature during clutch engagement is investigated in thermo-mechanical simulations. Consecutive static mechanical and transient thermal simulations were performed. Only the main synchronization phase is simulated, the pre-synchronization is neglected. The engagement is divided into several steps. Firstly, the deformation under static load is calculated. Both pressure distribution and displacement are input data for the heat flux calculation on the friction surface. The resulting temperature field of the thermal simulation is then again input parameter for the static mechanical simulation. The simulation ends, when the kinetic energy of the inertia is completely transferred into heat. The simulations aim to evaluate pressure and temperature distribution on the friction surface. Acuner [12] and Mileti [22] developed the simulation code based on the concept of [19] and [4]. In this paper, it was adapted to the requirements of the investigated multi-cone synchronizers. Mileti [22] et al. give a detailed description of the simulation process and their rig tests correlate well with the simulated temperatures.
Table 3 Material parameters for the thermo-mechanical simulation [19]

\begin{tabular}{lll}
\hline Parameter & Steel & Carbon \\
\hline$E / \mathrm{N} / \mathrm{mm}^{2}$ & 210,000 & 800 \\
$\nu /-$ & 0.30 & 0.25 \\
$\alpha_{L} / 10^{-6} 1 / K$ & 13 & 70 \\
$\lambda / \mathrm{W} / \mathrm{mK}$ & 43.5 & 0.5 \\
$\varrho / \mathrm{kg} / \mathrm{m}^{3}$ & 7850 & 1100 \\
$C_{p} / \mathrm{kJ} /(\mathrm{kgK})$ & $540[27]$ & 1500 \\
\hline
\end{tabular}

All simulations are 2D, performed with Ansys APDL, and post processed with Matlab. At the beginning, the axial force is raised from zero to the predetermined value within $0.1 \mathrm{~s}$. For the comparison of different synchronizer systems, their friction surfaces were meshed with the same element type and size. In every load stage, only one cycle is simulated with adiabatic boundary conditions. The $\mathrm{CoF}$ throughout the whole engagement process is set constant to 0.1. Table 3 summarizes the material parameters used in the simulation. Due to these restrictions and the fact that the contact surfaces are assumed to be smooth in the simulation, the evaluated maximum temperatures represent reference temperatures. In a convergence analysis for the triple cone synchronizer, the influence of the mesh size on the maximum temperature was evaluated. A further refinement of the mesh did not change the maximum friction surface temperature.

\section{Results and discussion}

Fig. 7 shows influences of different load parameters on the deterioration of the double cone synchronizer DK73. The deterioration of the synchronizer system increases with higher surface pressures and, respectively, higher friction
Fig. 7 Influence of load parameters on deterioration of synchronizer DK73-a $\vartheta_{\text {oil }}=80^{\circ} \mathrm{C}$ (variation $p$ ) $\mathbf{b} \mathrm{q}=0.9 \mathrm{~J} / \mathrm{mm}^{2}$, $\vartheta_{\text {oil }}=80^{\circ} \mathrm{C}$ (variation $\mathrm{vg}_{\mathrm{g}}$ ) c LS3 $\left(p=4.0 \mathrm{~N} / \mathrm{mm}^{2}, \mathrm{vg}_{\mathrm{g}, \max }=8.0 \mathrm{~m} / \mathrm{s}\right.$, $\mathrm{q}=0.7 \mathrm{~J} / \mathrm{mm}^{2}$, variation $\vartheta_{\text {oil }}$ )

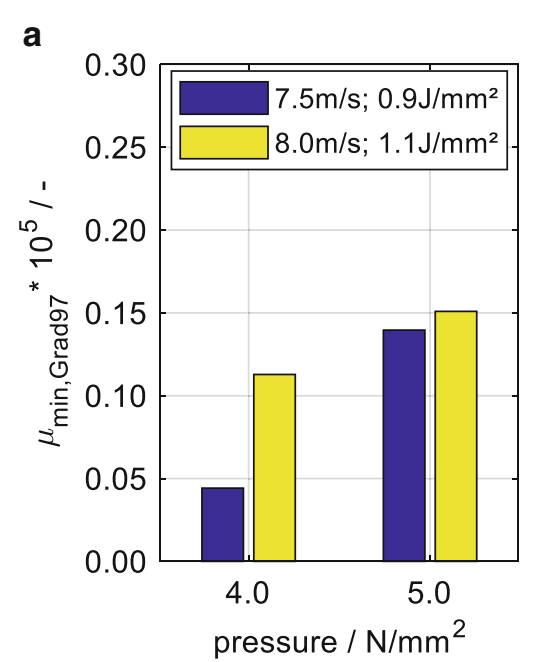

b

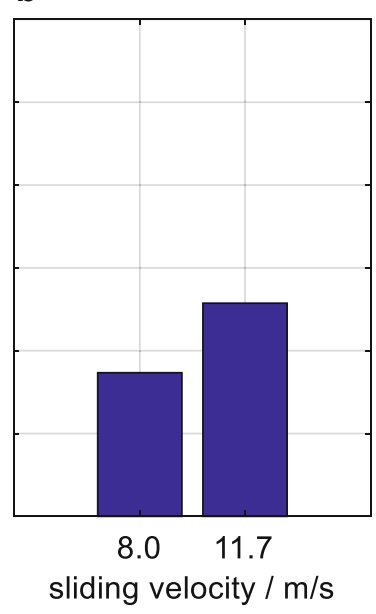

C

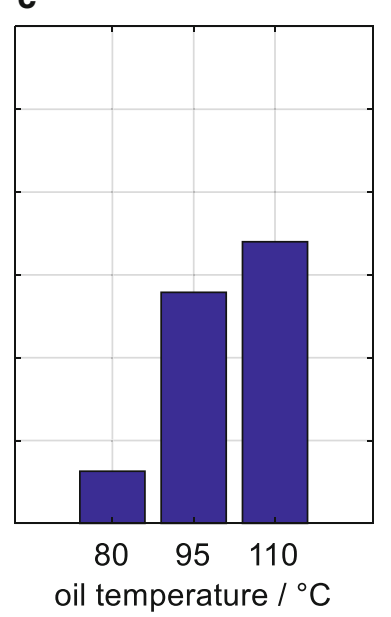


power (Fig. 7a). $\mu_{\min , \text { Grad97 }}$ slightly differs between the two tests with $p=5.0 \mathrm{~N} / \mathrm{mm}^{2}$. To evaluate the influence of the maximum sliding velocity, both specific work, and specific power were kept constant, and surface pressure, and sliding velocity were set to values given in Fig. 7. Higher sliding velocity leads to greater damage (Fig. 7b). The oil temperature is observed to highly influence the endurance life. Three tests were run on LS3 and the endurance life and $\mu_{\text {min,Grad97 }}$ were evaluated. Increasing $\vartheta_{\text {oil }}$ from 80 to $95^{\circ} \mathrm{C}$ reduces the cycles till failure by a factor of 4 . $\mu_{\min , \mathrm{Grad} 97} \mathrm{sig}$ nificantly increases when $\vartheta_{\text {oil }}$ is increased (Fig. 7c). Comparing the endurance life of both tests with $\vartheta_{\text {oil }}=95 / 110^{\circ} \mathrm{C}$, the amount of cycles till failure is halved from 14,785 to 7285 cycles.

Fig. 8 shows the trend plot of three tests on the same load stage. $\mu_{\text {avg }}$ is similar at the beginning of each test. However, the gradient of the three synchronizer systems' $\mu_{\min }$ differ. Due to their different locking safety, the three synchronizer systems fail at different levels of $\mu_{\min }$. This explains why we characterize the deterioration behavior using $\mu_{\min \text {,Grad97. }}$ The single cone synchronizer exhibits both the shortest endurance life and the biggest gradient of $\mu_{\min }$ within LS9, shown in Fig. 9.

The load parameters' influence on the deterioration behavior depends on the type of synchronizer (single, double or triple cone). Fig. 9 summarizes the results of 24 tests. Tests with the same friction work exhibit greater damage (higher $\mu_{\text {min,grad97 }}$ ) when the sliding velocity and, respectively, the friction power is increased. An increased sliding velocity increases the peak friction power at the beginning of the engagement and, therefore, higher surface temperatures occur. Comparing load stages with the same friction power/sliding velocity, $\mu_{\min , g r a d 97}$ is shown to increase with friction work. During life cycle tests at the same specific

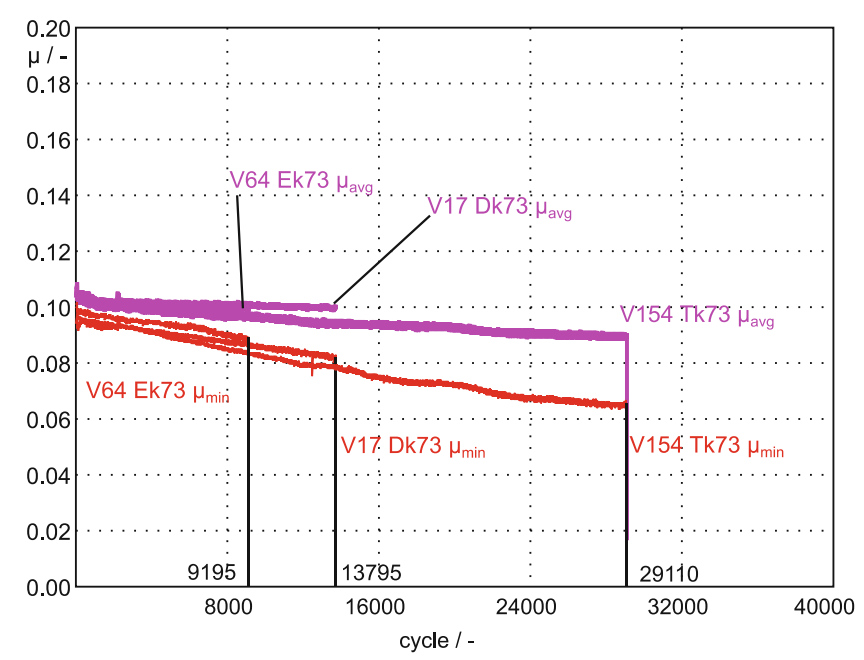

Fig. 8 Deterioration of single and multi-cone synchronizers-Trend plot V64 (EK73), V17 (DK73), V154 (TK73), LS9 $\left(p=4.0 \mathrm{~N} / \mathrm{mm}^{2}\right.$, $\left.\mathrm{q}=1.1 \mathrm{~J} / \mathrm{mm}^{2}, \mathrm{vg}_{\mathrm{g}, \max }=8.0 \mathrm{~m} / \mathrm{s}\right) ;$ MTF-Car, $\vartheta_{\text {oil }}=80^{\circ} \mathrm{C}$
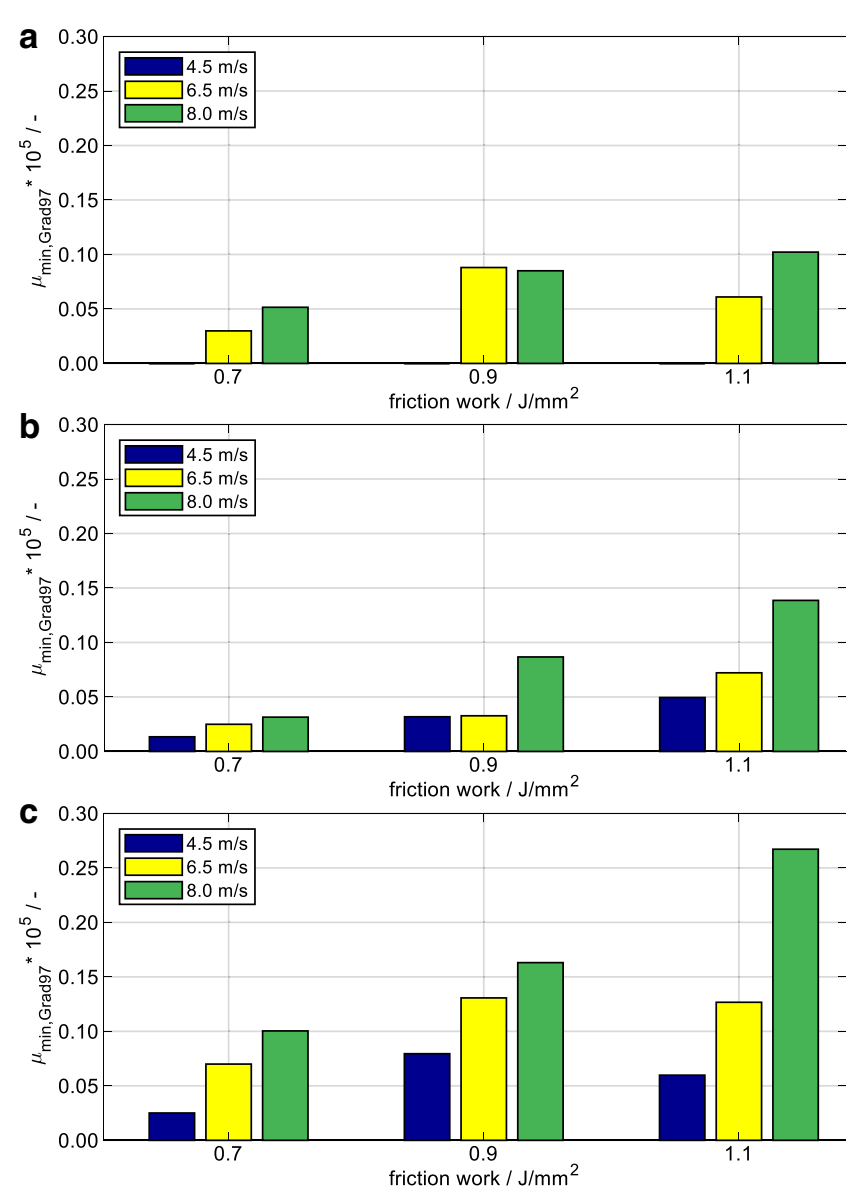

Fig. 9 Influence of load parameters on $\mu_{\min , \mathrm{Grad} 97}$ for single and multicone synchronizers, MTF-Car; $\vartheta_{\text {oil }}=80^{\circ} \mathrm{C}$. a TK73, b DK73, c EK73

load level, the single cone synchronizers, contrary to expectations, displayed greater damage compared to the multicone synchronizers. The deterioration is similar for double and triple cone synchronizers, except for two tests at $\mathrm{q}=0.9 \mathrm{~J} / \mathrm{mm}^{2}$ and $\mathrm{v}_{\mathrm{g}, \max }=6.5 \mathrm{~m} / \mathrm{s}$.

Fig. 10 combines results from rig testing (deterioration of synchronizers, rated with $\left.\mu_{\text {min,grad97 }}\right)$ with the maximum

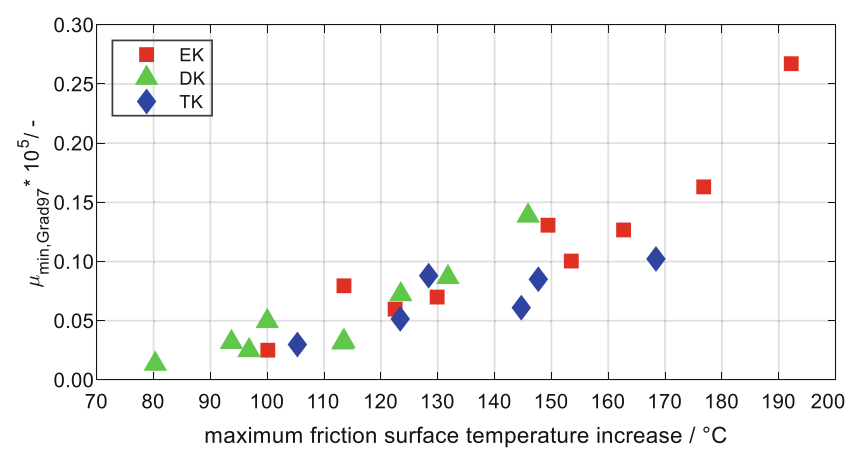

Fig. 10 Influence of maximum friction surface temperature increase

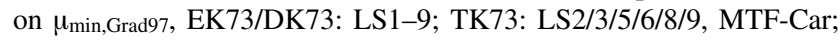
$\vartheta_{\text {oil }}=80^{\circ} \mathrm{C}$ 
friction surface temperature increase observed in the $2 \mathrm{D}$ thermo-mechanical simulations. The maximum surface temperature increase was calculated via simulations, for each test shown in Fig. 9. Higher maximum temperature increases lead to greater deterioration of the synchronizer system. FEM simulations show, that the blocker ring of the single cone synchronizer deforms more than that of the double cone synchronizer, causing a more unsteady pressure distribution on the friction surface. This results in higher local surface temperatures on the friction surface of the single cone synchronizer and, therefore, a greater deterioration of friction lining and lubricant. Roughness measurements of the surfaces confirmed an unsteady, smoothened friction surface. Erdmann [4] confirms a nonuniform pressure distribution for synchronizer rings in the axial and circumferential direction due to deformation of the non-axisymmetric synchronizer rings under axial load.

Increasing maximum surface temperature results in greater deterioration of the synchronizer system. These findings correlate well with Häggström et al. [14] who describe the focal temperature increase as a suitable parameter to predict failure of Mo synchronizers.

\section{Conclusion}

Load limits for single and multi-cone synchronizers with carbon friction lining used in cars were determined experimentally using the component test rig SSP-180. The specific value $\mu_{\min , \text { Grad97 }}$ proved suitable to compare deterioration behavior of different synchronizer systems as well as the influence of load parameters on the deterioration behavior. All synchronizers failed because the values of the coefficient of friction at the beginning of the clutch engagement were too low. During life cycle tests at the same specific load level, single cone synchronizers, displayed greater damage compared to multi-cone synchronizers. The bigger deformation of the single cone's blocker ring, compared to that of the multi cone synchronizers, caused a more unsteady pressure distribution on the friction surface, which resulted in higher local temperatures of the single cone synchronizer and, therefore, a greater deterioration of friction lining and lubricant. Thermo-mechanical simulations, in combination with experiments on the test rig, show that the maximum temperature during the engagement has a significant influence on the endurance life of synchronizers with carbon friction lining.

Acknowledgements The authors wish to thank FVA and the companies and their staffs who supported the projects. An extract from these results was presented at Dritev-Getriebe in Fahrzeugen 2019 in Bonn.
Funding The results presented were achieved in research projects sponsored by Forschungsvereinigung Antriebstechnik e.V. (FVA, http://www.fva-net.de).

Funding Open Access funding provided by Projekt DEAL.

Open Access This article is licensed under a Creative Commons Attribution 4.0 International License, which permits use, sharing, adaptation, distribution and reproduction in any medium or format, as long as you give appropriate credit to the original author(s) and the source, provide a link to the Creative Commons licence, and indicate if changes were made. The images or other third party material in this article are included in the article's Creative Commons licence, unless indicated otherwise in a credit line to the material. If material is not included in the article's Creative Commons licence and your intended use is not permitted by statutory regulation or exceeds the permitted use, you will need to obtain permission directly from the copyright holder. To view a copy of this licence, visit http://creativecommons.org/licenses/by/4. $0 /$.

\section{References}

1. Socin RJ, Walters LK (1968) Manual transmission synchronizers. SAE technical paper series. SAE International, Warrendale

2. Naunheimer H, Bertsche B, Lechner G et al (2007) Fahrzeuggetriebe: Grundlagen, Auswahl, Auslegung und Konstruktion, 2nd edn. Springer, Berlin, Heidelberg

3. Pingale A (2014) Development of compact synchronizer technology for manual and automated transmissions. SAE technical paper series. SAE International, Warrendale

4. Erdmann K (2008) Einflussfaktoren auf die Leistungsfähigkeit von Mehrfachsynchronisierungen. Dissertation. Leibniz Universität, Hannover

5. Sykes LM (1994) The Jaguar XJ220 triple-cone synchronizer a case study. SAE technical paper series. SAE International, Warrendale

6. Abdel-Halim NA, Barton DC, Crolla DA et al (2000) Performance of multicone synchronizers for manual transmissions. Proc Inst Mech Eng D 214(1):55-65. https://doi.org/10.1243/ 0954407001527213

7. Okazaki Y, Komatsuzaki K (1990) Double cone synchronizer with paper lining for medium duty trucks. SAE technical paper series. SAE International, Warrendale

8. Bamane S, Sonawane P (2016) Multi cone synchronizer system: a review. Int J Sci Res Dev 4:616-621

9. D’Orazio A, Caudano M, Uberti M et al (2001) GUDA-4 multi cone synchronizer dynamic modeling and experimental bench test rig to improve manual transmission shiftability (gear unit design and applications). In: Proceedings of the JSME international conference on motion and power transmissions, pp 649-656 https://doi.org/10. 1299/jsmeimpt.II.01.202.649

10. Rank R (1995) Untersuchungen zur Lebensdauerprüfung von Synchronisierungen. Dissertation, TU München

11. Acuner R, Pflaum H, Stahl K (2016) Tribologische Schädigungsmechanismen von Synchronisierungen mit Carbon-Reibwerkstoffen. In: FVA (ed) GETLUB - Tribologie- und Schmierstoffkongress, pp 239-251

12. Acuner R (2016) Synchronisierungen mit Carbon-Reibwerkstoffen unter hohen und extremen Beanspruchungen. Dissertation, TU München. Verlag Dr. Hut, München

13. Wanli X, Wei Z, Bin S et al (2015) Investigation of manual transmission synchronizer failure mechanism induced by interface material/lubricant combinations. Wear 328-329:475-479. https://doi. org/10.1016/j.wear.2015.03.024

14. Häggström D, Sellgren U, Björklund S (2018) Evaluation of synchronizer loading parameters and their ability to predict failure. 
Proc Inst Mech Eng J 232(9):1093-1104. https://doi.org/10.1177/ 1350650117738395

15. Osanai H, Ikeda K, Kato K (1990) Relations between temperature in friction surface and degradation of friction materials during engaging of wet friction paper. SAE technical paper series. SAE International, Warrendale

16. Maeda M, Murakami Y (2003) Testing method and effect of ATF performance on degradation of wet friction materials. SAE technical paper series. SAE International, Warrendale

17. Häggström D (2018) Towards model-based development of heavy truck synchronizers. Dissertation, KTH Royal Institute of Technology

18. Acuner R, Voelkel K, Pflaum H et al (2014) Influence of cone-angle-difference on performance of synchonizers with carbon friction linings. In: VDI (ed) Getriebe in Fahrzeugen 2014. VDI-Berichte, vol 2218, pp 595-610

19. Neudörfer S (2008) Thermomechanische Einflüsse auf die Tribologie von Synchronisierungen. Dissertation, Leibniz Universität Hannover

20. Poll G, Spreckels M (2003) Influence of temperature distribution on the tribological performance of automotive synchronisers. In: Tribological Research and Design for Engineering Systems, Proceedings of the 29th Leeds-Lyon Symposium on Tribology, vol 41. Elsevier, Amsterdam, pp 613-621

21. Spreckels M (2001) Einfluss der Temperaturverteilung auf das tribologische Verhalten von Synchronisierungen. Dissertation, Leibniz Universität Hannover
22. Mileti M, Pflaum H, Stahl K (2018) TorqueLINE cone clutch: thermo-mechanical stability of cone clutches for ATs. In: Dritev: International VDI Congress Dritev-Drivetrain for Vehicles, EDrive, Transmissions in Mobile Machines Bonn, 27 June 2018 VDI, Düsseldorf (Nichtredigierter Manuskriptdruck)

23. Häggström D, Sellgren U, Stenström W et al (2015) A verified and validated model for simulation-driven design of heavy duty truck synchronizers. In: ASME 2015 Power Transmission and Gearing Conference; 23rd Reliability, Stress Analysis, and Failure Prevention Conference ASME. vol 10 (V010T11A045)

24. Häggström D, Stenström W, Sellgren U et al (2015) Parameter study of the thermomechanical performance of heavy duty synchronizers. In: VDI (ed) Getriebe in Fahrzeugen 2015. VDIBerichte, vol 2256, pp 597-620

25. Häggström D, Sellgren U, Björklund S (2018) The effect of manufacturing tolerances on the thermomechanical load of gearbox synchronizers. Procedia CIRP 72:1202-1207. https://doi.org/10.1016/ j.procir.2018.03.050

26. Stockinger U, Pflaum H, Stahl K (2019) Single vs. multi-cone synchronizers with carbon friction lining - a comparison of load limits and deterioration behavior. In: Dritev. VDI, Düsseldorf (Nichtredigierter Manuskriptdruck)

27. Richter F (1983) Physikalische Eigenschaften von Stählen und ihre Temperaturabhängigkeit: Polynome und graphische Darstellungen; Mitteilung aus dem Forschungsinstitut der Mannesmann AG. Stahleisen-Sonderberichte, vol 10. Stahleisen, Düsseldorf 